\title{
Caciquismo y sociedad en Osuna durante el reinado de Alfonso XIII
}

\author{
JOSE MANUEL RAMIREZ OLID
}

\section{INTRODUCCION}

El término de Osuna se extiende en gran parte por la Campiña sevillana, zona donde se alternan inmensos cortijos y haciendas de olivar con algunas dehesas para la cría de ganado. Al no tener un río de consideración su agricultura ha sido exclusivamente de secano.

Conquistada a los musulmanes por Fernando III, en 1264 Alfonso X

la erigió en encomienda mayor de la orden de Calatrava. Siglos después, el controvertido Pedro Girón, maestre de Calatrava, cambió a la orden Fuente-Ovejuna y Belmez por Osuna. A partir de entonces entró Osuna en la órbita de los Girones. En 1562 Felipe II concedió a Pedro Téllez-Girón el título de duque de Osuna.

Hasta 1886 la mayor parte del término de Osuna era propiedad de la casa ducal, que poseía doscientos veintinueve cortijos con un total de 24.702 fanegas de tierra, de las cuales la mayoría estaban en manos de grandes arrendatarios que formaban las familias dominantes de la localidad.

El duque Mariano Téllez-Girón llevó la casa a la ruina total. Tras su muerte en 1882 empiezan las subastas de fincas, que pasan en su mayoría a los grandes agricultores arrendatarios de las mismas. Se crea, pues, un grupo de latifundistas integrados por familias de la nobleza local hidalgos en su mayor parte- y por burgueses enriquecidos a la sombra de la casa ducal.

Con una población de hecho en torno a los veinte mil habitantes, la base de su economía se encontraba casi exclusivamente en una agricultura extensiva y latifundista. Ello ocasionó unas diferencias económicas y sociales enormes, donde más del 75 por 100 de la población era jornàlera somet da a las vicisitudes meteorológicas y a paros estacionales, que algunios años llegaron a revestir tintes dramáticos.

Las formas peculiares de la sociedad ursaonense explican la configuración del caciquismo local. Por ello hemos procurado enmarcar el 
trabajo dentro del contexto social -especialmente de las clases dominantes- de la Osuna del reinado de Alfonso XIII, entendido este período en su sentido más amplio, es decir, desde su nacimiento en 1886 hasta la proclamación de la Segunda República.

\section{CARACTERISTICAS DE LA SOCIEDAD URSAONENSE}

El haber sido Osuna durante tanto tiempo una villa de señorío perteneciente a una de las familias más importantes de la nobleza española, su distanciamiento de la capital y el establecimiento en la misma de personas muy vinculadas a la casa ducal como empleados de ésta o en virtud de una descendencia bastarda de los duques y sus amigos, aspecto sin estudiar, pero que mantenemos como hipótesis para futuras investigaciones, dieron a la sociedad ursaonense una configuración peculiar, muy diferente de las de su entorno, donde un clasismo a ultranza y anacrónico ha sido uno de los rasgos más distintivos. De ahí que en el aspecto social Osuna no camine al mismo paso que el resto de España. Raymond Carr apunta como peculiaridad más destacada de la sociedad española de la Restauración dla unión en una clase única de la aristocracia y de los propietarios no pertenecientes al estamento nobiliario.. ${ }^{1}$ Sin embargo, esto no lo encontramos en Osuna.

El panorama que presentan las clases altas responde al esquema general, donde una nobleza y una burguesía agrarias se han enriquecido al socaire de la descomposición y ruina de la casa ducal. En efecto, ambas centran su poder económico, y por ende político y social, en la posesión de la tierra, pero el acercamiento y la unión entre ambos grupos no se produce, a pesar de moverlas los mismo intereses económicos, de frecuentar los mismos círculos de recreo y de compartir un ideario semejante. La fusión no se realiza por el cerramiento a cal y canto de la nobleza a admitir en sus familias a advenedizos, algunos quizá más ricos que ellos, pero de inferior condición social. Y tal como ocurre en las sociedades de estructuras muy rígidas, este cerramiento marcado por la cúpula se hará extensible a los estratos inferiores.

En efecto, uno de los indicadores que consideramos más fiables para detectar el grado de clasismo en una sociedad es el matrimonio. Constituye en sí la máxima expresión de unión/desunión de clases, porque el enlace conyugal conlleva no sólo la unión de dos personas, sino de dos familias con una descendencia común a ambas. Y aquí es donde la nobleza ursaonense pone pie en pared para impedir cualquier

(1) CARR, Raymond: España: de la Restauración a la Democracia. Barcelona, Ariel, 1988, pág. 58 
tipo de unión morganática. Hasta bien entrado el $\mathrm{S}$. XX la endogamia nobiliaria es absoluta. A partir de los años treinta se aprecia una incipiente apertura hacia la alta burguesía en algunas familias, mientras la mayoría mantiene sus puertas cerradas a los advenedizos, por muy cargadas de dinero que traigan sus alforjas.

Como apuntábamos anteriormente, igual ocurre con las clases inferiores. La alta burguesía practicará también la endogamia utilizando como baremo la fortuna personal traducida en la posesión de la tierra. Al pretendiente de una hija o a la pretendida de un hijo se le mira el número de fanegas de tierra que tenga en potencia o en acto. $Y$, en consecuencia, quedan descartados los que no posean tierras en cantidad semejante a la de ellos. Ni siquiera admiten a profesionales universitarios -médicos, abogados- a los que despectivamente llaman señoritos de corbata y tirilla tiesa*: Del mismo modo, las clases medias practican la endogamia respecto a las clases humildes, que ven imposibilitado cualquier intento de acceder por vía matrimonial a un statu superior.

En definitiva, los deseos y los rechazos son comunes a todos los grupos sociales. La burguesía aspira a emparentarse con la nobleza y las clases medias con la burguesía, pero tanto en un caso como en otro encontrarán siempre la oposición del grado superior.

Una sociedad tan rígidamente estructurada no tiene más remedio que reflejar en todos sus comportamientos las peculiaridades que hemos apuntado. Los grupos dominantes, nobleza y alta burguesía, se reparten sus respectivos campos de acción. En el ámbito político la nobleza se alinea con los conservadores, mientras la burguesía lo hace con los liberales. En el Casino de Osuna, la sociedad recreativa más importante de la época, ambos grupos se alternan en la directiva de manera inversa a como lo hacían los partidos políticos: cuando el Ayuntamiento está en manos de los conservadores, el Casino está dirigido por liberales y al contrario. De otra parte, una sociedad que mantiene intactas sus manifestaciones externas de carácter religioso, no podía dejar de delimitar los campos de acción de uno y otro grupo. Las dos cofradias más importantes por el número de hermanos y por el fervor que convocaban -Jesús Nazareno y la Virgen de los Dolores- resumen y sintetizan con mayor evidencia este comportamiento que venimos describiendo. Las dos hacen el recorrido procesional el mismo día, Viernes Santo, a la misma hora una detrás de otra por las mismas calles del pueblo, tienen su sede en la misma iglesia, la Victoria, pero están separadas, son dos hermandades distintas. La junta directiva de la hermandad de la Virgen de los Dolores estaba monopolizada por la nobleza y la de Jesús Nazareno por la alta burguesía. Igual que en otros comportamientos humanos están juntos, pero separados. 


\section{DISEÑO DEL CACIQUISMO LOCAL}

\section{Consideraciones generales}

Uno de los emblemas más distintivos del régimen de la Restauración es el caciquismo. Aunque éste no es hijo de ella, es, empero, en la España de la Restauración donde encontrará un terreno fértil para su crecimiento. Aparentemente el régimen es constitucional y parlamentario, pero en la práctica es una oligarquía que hace y deshace, pone y quita según sus conveniencias sin tener en cuenta preceptos legales, morales o éticos, dando lugar a una situación donde la teoría y la práctica se encuentran en el más absoluto de los divorcios.

Si hay algo que diferencia a esta oligarquía de la de épocas anteriores, es que el poder no será monopolio de las clases altas económicas y sociales, y de los políticos notables llegados a la vida pública en función de su posición social dada por su cuna, riqueza o capacidad intelectual, sino que aparecen en la escena política otros miembros del espectro social que hasta entonces, por su condición humilde, estaban marginados de los asuntos públicos. Se trata del político de oficio, un hombre que ha encontrado en la política su medio de vida.

El sistema político de la Restauración, por su propia naturaleza, favorecería a los políticos de oficio, a los muñidores sin escrúpulos en perjuicio de los hombres independientes y de valía, que hubieron de ceder "el puesto a los intrigantes que especulaban con los manejos de los votos. ${ }^{2}$

Pero cuando se habla de caciquismo o de política caciquil no nos referimos exclusivamente a la persona que ejerce un poder omnímodo en un lugar, sino a una amplia red que se extiende por toda España entrelazada por pactos, intereses y favores. Por ello, no se puede hablar de un cacique, sino de varios; imponiéndose una diferencia jerárquica, pero perfectamente concatenada entre los distintos componentes de la trama caciquil. De hecho se pueden distinguir tres tipos de caciques: el de altura o de Corte, el cacique provincial y el cacique rural. ${ }^{3}$ Los tres se requieren. El de Corte necesita al provincial para que le gane las elecciones, el provincial al rural para que le facilite el triunfo electoral; pero la dependencia no es sólo de arriba a abajo, lo que sería fácil de romper, sino también a la inversa, con lo cual se forma un bloque entrelazado de dureza diamantina: el cacique rural necesita al provincial para que haga oídos sordos a las quejas y vista gorda a las denuncias de las irregularida-

(2) VARELA ORTEGA, José: Los amigos polúticos. Madrid, Alianza Editorial, 1977, pág. 366

(3) Véase VILLAESPESA CALVACHE, Vicente: El funesto caciquismo y algo de su terapia. Madrid, Tipografía J. Fernández Murcia, 1908, págs. 17 y ss. 
des cometidas por su enorme poder, que sin el respaldo del cacique provincial desaparecería automáticamente, y le facilite los favores que justifican su cacicato. E igualmente ocurre con la dependencia del cacique provincial con el de Corte.

La finalidad del caciquismo como organización es el control político, que viene dado por la desmovilización del electorado. Es, pues, el trabajo fundamental del cacique: apartar a la masa de la vida política y, como consecuencia del desinterés de ésta, monopolizarla unos pocos.

De otra parte, caciquismo y riqueza no tienen porqué estar unidos, a pesar de la manoseada imagen de presentar al cacique como el más rico de la localidad, porque el poder del cacique no se basaba en su riqueza, sino en la habilidad para manejar a su antojo y conveniencia la maquinaria administrativa. De ahí que sea muy frecuente encontrar entre los caciques a profesionales del Derecho y funcionarios públicos, cuya experiencia y conocimiento de la administración les permitían jugar con ella a tenor de las circunstancias.

Pero estas consideraciones no pueden llevarnos a separar capital y caciquismo, porque el capital se integra en el sistema y forma parte de la clientela del cacique colaborando con él a través de su poder económico, para ser recompensado con el arreglo del camino que conduce a su finca, con una mayor vigilancia de sus propiedades, con la rebaja de los consumos o con recomendaciones en la capital. E igualmente será castigado si no colabora con el cacique. Ello obligó a muchos ricos a desembarcar en la política como caciques o colaboradores, para mantener su poder económico, que, de otro modo, peligraba porque como dijo otro, con un sistema que todo lo penalizaba 'no había otro remedio que ser carne o cuchillo.' Había que mandar, aseguraba un cacique andaluz, por 'instinto de conservación.' En efecto, al estar la justicia mezclada con la Administración, las leyes no regían para los amigos, sino, como reconocía Silvela 'para servir a los amigos y perseguir a los adversarios. ${ }^{\prime} * 4$

Así pues, en el control de la Administración y de la Justicia, y no en su riqueza personal reside el poder del cacique, que reparte cosas pertenecientes a la jurisdicción municipal, provincial o estatal, pero no a su patrimonio: permisos de obras, licencias para abrir comercios o ejercer profesiones, absoluciones judiciales, condonaciones de multas o exenciones del servicio militar.

Javier Tusell ha puesto de manifiesto que no todos los caciques eran unos déspotas corruptos y nepóticos, sino que existía también un -cacique bueno", que gozaba de gran popularidad y simpatía, que repartía favores con generosidad y no utilizaba su situación privilegiada para

(4) VARELA: Op. cit, págs. 368 y 356 
enriquecerse, resultando con frecuencia "beneficioso para la ciudad o la región en que está implantado..$^{5}$

Centrándonos en el caso de Osuna, el cacicato se ejerce desde el exterior a través de los Diputados a Cortes, y desde el interior mediante la acción de los jefes de los partidos o de los prohombres de éstos que en algunas ocasiones prefieren mantenerse a la sombra.

\section{Los diputados a Cortes}

Decía un semanario osunés de la década de los ochenta que los auténticos caciques eran los Diputados a Cortes. No exageraba el periódico, sobre todo en aquellos años en que el distrito de Marchena, donde se integraba Osuna, estaba controlado por Francisco de Paula Candau Acosta, que desde 1861 hasta diciembre de 1883 representó al distrito, a excepción del sexenio revolucionario. A partir de entonces, el distrito, que se había caracterizado por la estabilidad, se va acoplando a la dinámica del turnismo ante la ausencia de un hombre con la suficiente capacidad para imponerse en su demarcación y la necesaria influencia en la Corte para que le respetaran el encasillado. La muerte de Candau, pues, abre un periodo de lucha entre conservadores y liberales, unos para que el distrito entre en el juego del turnismo, los otros para mantener el monopolio que venían disfrutando. Pero ninguno de los dos partidos del turno llegará a imponerse con la fuerza necesaria.

El Partido Conservador, una vez muerto Candau, procuró romper el monopolio liberal sobre el mismo, recurriendo a cuantos medios estuvieron a su alcance, como demostraron las elecciones de 1884. Pero los conservadores fallaron en la designación del hombre que había de hacerse fuerte en el distrito. José Torres y Díez de la Cortina no tenía arraigo ni prestigio, aparte de no estar bien considerado por su pasado carlista ni siquiera entre los miembros de su propio partido. Ello ocasionó una división entre los conservadores de Osuna. El hasta entonces jefe conservador Aniceto de la Puerta Zayas y su preconizado sucesor, su sobrino Cristóbal de la Puerta Govantes, se alinearon junto a los elementos más liberales del conservadurismo osunés en las filas de Silvela, mientras ex-carlistas y neos decantaban sus simpatías por el sector de Romero Robledo, representado por el diputado a Cortes José Torres y Díez de la Cortina. Y divididos se mantienen durante todo el periodo constitucional, primero entre romeristas y silvelistas, después entre datistas y mauristas, sin conseguir, por ello, una fuerte implantación en el distrito, ni siquiera en el ámbito local.

(5) TUSELL, Javier: Oligarquía y caciquismo en Andalucía, 1890-1923. Barcelona, Planeta, 1976, pág. 330 
La situación del Partido Liberal es distinta, aunque el resultado es semejante. Monopolizador del distrito durante la etapa de Candau, los liberales se resistieron a perder su feudo y procuraron por todos los medios imponer a la familia Ruiz-Martínez como sucesores del diputado fallecido. Más cohesionado al principio que los conservadores, los liberales pudieron mantener su protagonismo en el distrito, pero una serie de circunstancias lo impidieron. De una parte, el patriarca de la familia, Francisco Ruiz Martínez centró su interés en acaparar la jefatura de los liberales sevillanos, y de hecho ejerció como tal durante algún tiempo, pero fue desbancado primero por el marqués de Paradas y después por Pedro Rodríguez de la Borbolla, conformándose con una senaduría vitalicia y un título de barón. De otra, la familia Ruiz-Martínez no acertó a la hora de calibrar donde se encontraba la fuerza en el distrito, declinando sus preferencias por Marchena en perjuicio de Osuna, cuando este último pueblo era el de mayor peso electoral, además de contar con familias muy influyentes en la provincia.

La pérdida de la posibilidad de un cacicazgo liberal estable en Osuna vino dada por la supresión del Juzgado de Primera Instancia e Instrucción de Osuna a finales de agosto de 1893. Tras los hechos consumados empiezan las movilizaciones. Todos culpan al diputado a Cortes del distrito Cándido Ruiz-Martínez, que negoció con el ministro de Justicia el mantenimiento del Juzgado de Marchena a cambio de suprimir el de Osuna. Cuando surgieron los rumores de una posible supresión del Juzgado, las autoridades locales acordaron formar una comisión y desplazarse a Madrid para tratar el asunto directamente con el ministro de Justicia. Pero RuizMartínez disuadió a sus peones instalados en el Ayuntamiento. Por ello, las autoridades municipales no hicieron en ningún momento oír su voz para impedir la supresión del Juzgado. En este asunto Cándido Ruiz-Martínez actuaba movido únicamente por intereses particulares. En Marchena, su familia poseía un enorme cortijo, Monte Palacio, donde, como en todas las fincas grandes, eran frecuentes los robos, daños, incendios, etc. Además, en Marchena su influencia era mayor que en Osuna, cuyo poder quedaba limitado a la clientela política. Ante la seguridad de que Marchena perdería su Juzgado por tener menos población, menos asuntos y menos tradición, el diputado no dudó en gestionar cerca del ministro el mantenimiento del Juzgado de Marchena a cambio de suprimir el de Osuna. Este fue el fin de la oportunidad de los Ruiz-Martínez para hacerse fuertes en el distrito, aunque lo continuaron representando cuando los liberales estaban en el poder. Pero el partido, que hasta entonces se había mantenido unido en el ámbito local, se fraccionó. Muchos liberales descontentos con el oscuro proceder de Ruiz-Martínez abandonaron sus filas y se pasaron a la oposición bajo la denominación de liberales disidentes. 
Tardaría años el partido liberal en encontrar a un hombre nuevo; desvinculado de las prácticas caciquiles de los Ruiz-Martínez y con el carisma suficiente para imponerse en el distrito. Esta oportunidad llegó con Juan José Serrano Carmona. Las elecciones a diputados a Cortes de 1910 fueron novedosas en el distrito de Marchena: por primera vez en veintiséis años se presentaba un candidato liberal encasillado que no pertenecía a la familia de los Ruiz-Martínez. Era Juan J. Serrano Carmona un abogado y periodista granadino afincado en Sevilla, que se perfilaba como uno de los hombres fuertes del canalejismo sevillano. Serrano Carmona en los cuatro años de diputado trabajó intensamente el distrito con frecuentes visitas a Osuna donde pensó comprar una casa para pasar largas temporadas en la villa ducal. ${ }^{6}$ Probablemente el diputado había sacado una lección del error de Ruiz-Martínez: aunque Osuna no fuera la cabecera del distrito, la fuerza de éste residía en ella. Pero la muerte de Canalejas frustró las expectativas de Serrano Carmona. Rodríguez de la Borbolla se hizo con el liderazgo de los liberales sevillanos en versión romanonista y Serrano Carmona se retiró de la política en julio de 1914 decepcionado por el trato que había recibido en las últimas elecciones por parte de Borbolla.

\section{Los caciques locales}

Como se ha visto, los partidos del turno por divisiones, personalismos y errores no lograron crear un cacicazgo estable a nivel de diputados a Cortes, lo que incidió en la configuración del cacicazgo local, que aparece confusa cuando no titubeante. Por ello no se puede hablar de un cacique, sino de varios en función no solo del partido en el poder, sino del sector al que perteneciera el diputado a Cortes del momento. Esta confusión es mayor hasta 1910 en los conservadores que en los liberales. El Partido Conservador con divisiones irreconciliables en cierto modo vinculadas no tanto a ideologías políticas, sino a posturas personales y familiares, vio repartido su poder entre las familias de los Torres-Linero y de los Puerta Govantes. Sin embargo, en este periodo el Partido Liberal a partir de sus disensiones y divisiones aparece mucho más unido por el cacicazgo fuerte que ejerce Leonardo Recio Reyes, el hombre de Candau y de los Ruiz-Martínez en Osuna.

Es, pues, un reflejo más de la sociedad ursaonense. Los caciques conservadores pertenecen a familias de la nobleza local, latifundista, que ostentan el poder en virtud de un apellido y precisamente por ello han sido destinados a ejercerlo. Sin embargo, en el Partido Liberal aparece el cacique nuevo que tanto difundiría el régimen de la Restauración. No es

(6) -El Paleto., n² 574, 25, septiembre, 1913 
un miembro de las familias y los grupos dominantes, no tiene fortuna familiar ni personal, pero cuenta con una sólida formación jurídica y administrativa que le permite una hábil interpretación de las leyes. Leonardo Recio era notario.

En la segunda década del S. XX empieza a clarificarse la situación del Partido Conservador. Continúa dividido en dos grupos, el maurista y el datista representados por Jaime de Oriol y de la Puerta y por Cristóbal de la Puerta Govantes respectivamente. Estos últimos años del régimen constitucional coinciden con la decadencia física de Cristóbal de la Puerta y con el inicio del apogeo de Jaime de Oriol, que con el paso de los años se convertirá en el hombre fuerte de la derecha ursaonense. Mientras tanto, un tercer hombre con título nobiliario y primer contribuyente de la localidad hace su aparición en la escena política probablemente por rivalidad personal con Jaime de Oriol: el marqués de la Gomera. Antonio Tamayo Contreras llega en un momento en el que los puestos rectores de los grupos conservadores estaban ocupados por Oriol y Puerta. Sin embargo, los liberales estaban acéfalos. La desaparición física de Leonardo Recio y la retirada de Eduardo Fernández Zamora siguiendo los pasos de Serrano Carmona habían dejado a los dos grupos liberales, romanonistas y garciprietistas, sin cabezas rectoras. Y esta situación la aprovecha el marqués de la Gomera para tratar de aunar en torno a su persona a los liberales ursaonenses. En septiembre de 1914 el marqués de la Gomera convoca a todos los liberales de Osuna a una reunión en su casa-palacio. No consigue su empeño de atraerse a los garciprietistas a las filas de Romanones, representado en Sevilla por Pedro Rodríguez de la Borbolla, pero sí que le reconozcan como jefe del borbollismo osunés. De todas formas, los liberales poco tenían que hacer y decir en la política local.

La Dictadura de Primo de Rivera abre un nuevo capítulo en la historia del cacicazgo local. Tras producirse el golpe de Estado, Jaime de Oriol y el marqués de la Gomera se enfrentan sin disimulos en una lucha abierta para hacerse con el poder local. El primer año de la Dictadura está marcado por el pulso que mantienen Oriol y Tamayo. Jaime de Oriol más dotado que el marqués de la Gomera a quién superaba en cultura, recursos dialécticos, capacidad de intriga y brillantez personal perdía terreno por momentos. En mayo de 1924 el marqués de la Gomera consolidaba su poder al ser nombrado jefe local de la Unión Patriótica. La vieja amistad de los Tamayo con los Primo de Rivera estaba dando sus frutos.

El 31 de diciembre de 1924 tomaba posesión una nueva Corporación municipal hecha a la medida del Marqués de la Gomera: el alcalde era su sobrino, el primer teniente de alcalde su cuñado, y antiguos liberales clientes suyos completaban el gobierno municipal, volviéndose al caciquismo que tan denostado había sido en los primeros días de la Dictadura. 
Sin embargo, el cacicazgo del Marqués de la Gomera difiere sustancialmente de los de la vieja política. Tamayo encarna en cierto modo la figura del buen cacique. Aprovechando su amistad con Primo de Rivera y las posibilidades hacendísticas y financieras que ofrecía el Estatuto Municipal de 1924, se propuso solucionar los problemas pendientes que tenía el pueblo desde hacía muchos años: la creación de un Instituto Nacional de Enseñanza Media y solucionar la escasez de agua potable, además de dotar al pueblo de una mejora en la infraestructura viaria y en la extensión de la red de alumbrado público.

Desde octubre de 1847 a julio de 1876 Osuna tuvo un Instituto Local de Segunda Enseñanza, cuya supresión no fue ajena a dudosos manejos caciquiles nada interesados en la presencia de un profesorado independiente que se le escapaba a sus influencias. ${ }^{7}$ Desde la supresión, algunos sectores de la sociedad ursaonense recurrieron a cuantos medios estuvieron a su alcance para conseguir su restitución. Pero todos los intentos resultaron fallidos, subsanándose esta deficiencia con un colegio privado subvencionado por el Ayuntamiento.

Estaba claro que las clases dominantes no querían un Instituto Nacional, pero el marqués de la Gomera se comporta en estos años como un desclasado, pues precisamente en aquello que los de su clase rechazaban por considerar que podía atentar contra sus intereses, pone el entusiasmo de un catecúmeno para conseguirlo. Aprovechando su amistad con Primo de Rivera y la presencia en Madrid de un ursaonés ilustre muy empeñado también en que Osuna volviera a tener un Instituto, Francisco Rodríguez Marín, a la sazón Director de la Biblioteca Nacional y vocal del Consejo de Instrucción Pública, organismo que necesariamente había de informar sobre la conveniencia de su creación, el marqués de la Gomera centró su interés en conseguir un Instituto para Osuna. En el pleno de 22 de abril de 1927 fuę aprobada la propuesta de la Comisión Permanente para solicitar al Gobierno la creación de un Instituto Nacional de Segunda Enseñanza. ${ }^{8}$ El 23 de julio de ese mismo año el Consejo de Ministros aprobaba la creación del Instituto de Osuna.

Igual empeño puso el marqués de la Gomera en solucionar el problema de la escasez de agua potable. Desde la segunda mitad del S. XIX se puso de manifiesto la insuficiencia del manantial que surtía de agua a Osuna, hasta llegar a situaciones dramáticas en los veranos con interminables colas de cántaros en unas fuentes secas la mayor parte del día. Las diversas corporaciones municipales teóricamente estuvieron empeñadas

(7) Véase RAMIREZ OLID, José Manuel: La enseñanza Secundaria en Osuna, 1847-1927. .Homenaje a D. Alfredo Malo. Sevilla, 1992, págs. 177-191

(8) Archivo Municipal de Osuna. Acta de Plenos, 22, abril, 1927, fols. 79-83 
en solucionar el problema, pero la realidad era muy distinta, como demuestran los diversos proyectos de abastecimiento de agua potable que llegaron al Ayuntamiento y fueron rechazados por éste: A medida que avanzan los años el problema aumenta, y también la resistencia de las clases dominantes a dotar a la población del agua suficiente. El abanderado de esta postura era Jaime de Oriol, que preveía una posible industrialización y un trasvase de obreros del campo a las nuevas industrias con el consiguiente aumento de sueldos y exigencias de los jornaleros, que ya habían mostrado su insatisfacción en las huelgas de 1914 y 1915. El marqués de la Gomera puso un enorme interés en dotar a Osuna de la suficiente cantidad de agua potable. El Ayuntamiento encargó un estudio de los manantiales más cercanos a Osuna a la Compañía Construcciones Hidráulicas y Civiles, S. A. En vista de los escasos resultados obtenidos en las proximidades de Osuna, en agosto de 1927 se desplazó a la villa Eduardo Torroja, ingeniero de la Compañía, para hacer un estudio de los manantiales más cercanos y designar el más conveniente para la población. Torroja se inclina por el manantial de Majavea, situado entre las poblaciones malagueñas de Almargen y Cañete la Real. Durante 1929 el Ayuntamiento hizo gestiones con el Banco de Crédito Local para que facilitara el dinero de las obras. Cuando ya parecía que todos los asuntos burocráticos y financieros estaban solucionados, cayó la Dictadura.

La caída de la Dictadura llevó aparejada la del marqués de la Gomera en el cacicazgo local y su relevo por Jaime de Oriol. El 24 de marzo de 1930 una nueva Corporación tomaba posesión. Los nuevos concejales que antiguamente habían militado en las filas liberales no asistieron al acto conscientes de que su alineamiento con el marqués de la Gomera los convertía ahora en unos marginados dentro del gobierno local. Reconocido por todos como el mentor de la nueva Corporación, Jaime de Oriol se vio obligado a desmentir el papel que le atribuían de muñidor de la nueva situación política, ${ }^{9}$ aunque nadie lo creyó. La nueva Corporación se apresuró a dar carpetazo a cuantos asuntos habían sido gestionados por el Ayuntamiento: anterior, especialmente a la traída de agua de Majavea, la bestia negra del nuevo cacique.

\section{REACCIONES ANTICACIQUILES}

Tuvo el caciquismo, como es natural, su contestación en Osuna. Una contestación que se distingue, de una parte, por lo reducido de las personas que abiertamente lo denunciaron y se opusieron, $y$, de otra, por

(9) A.M.O. Acta de Plenos, 24, marzo, 1930, pág. 26 
el declinar de las mismas hasta conseguir los grupos dominantes acallar definitivamente las voces y opiniones que les eran adversas.

El adalid de esta reacción es Francisco Rodríguez Marín, un joven abogado y escritor que en sus años de estudiante en Sevilla emprendió, desde el periódico "El Alabardero", una notable campaña contra el caciquismo osunés, que terminaría con el cierre del periódico en $1881 .{ }^{10}$

En 1883 Rodríguez Marín se traslada a Osuna, su pueblo natal, para abrir bufete al amparo de la recién creada Audiencia de lo Criminal. En Osuna, ya se estaba editando el periódico «El Ursaonense* en cuya creación tuvo mucho que ver Rodríguez Marín, y hacía muy pocos meses que había regresado también a su pueblo natal, después de sesenta años de ausencia, un viejo mito revolucionario: Antonio $\mathrm{M}^{2}$ García Blanco. ${ }^{11} \mathrm{Sa}-$ cerdote y catedrático de Hebreo de la Universidad de Madrid, a pesar de sus ochenta y tres años, mantenía intacto su entusiasmo contestatario. En estos años se formaron a la sombra del anciano hebraísta y del incipiente cervantista un reducido grupo de jóvenes que se distinguieron por su perseverancia en mantener informada a la población mediante la prensa local y su denodada lucha contra las prácticas caciquiles.

$\mathrm{El}$ medio de que se sirven, como ya hemos apuntado, es la prensa local. El primer periódico, *El Ursaonense (octubre 1882-diciembre 1885), lo edita un grupo de jóvenes con inquietudes intelectuales procedentes en su mayoría de familias de las clases medias y humildes que, por sus despejadas inteligencias y sacrificios personales y familiares, habían realizado algunos de ellos estudios universitarios. Ideológicamente están influenciados por el krausismo y políticamente son republicanos. El periódico lo dirige Enrique Rodríguez Durán, doctor en Ciencias y catedrático de Matemáticas de Instituto, aunque el verdadero factotum del mismo es Rodríguez Marín, que afirmó haber escrito ssolo y sin remuneración alguna "El Ursaonense. durante tres años. ${ }^{12}$ "El Ursaonense. critica a la nobleza local, cuyos privilegios saca a flote, como la cañería que conducía directamente el agua del manantial a la casa de los marqueses de la Gomera, mientras las fuentes públicas estaban secas y, en consecuencia, el pueblo sin agua. Más abundantes aún son las críticas a la gestión municipal, proceda del partido que proceda -en aquellos años hubo una corporación liberal, otra republicana y otra conservadora-, que será la fosa que a sí mismo se excavó .El Ursaonense». En efecto, presionado el director, que a

(10) Véase CASOS, M.- RODRIGUEZ MARIN, F.: El Gobernador de Sevilla y .El Alabardero. Sevilla, Imprenta de Gironés y Orduña, 1881

(11) Para su vida y su obra, véase: PASCUAL RECUERO, Pascual: Antonio $M^{\circ}$ Garcia Blanco $y$ el hebraísmo español del S. XIX. Universidad de Granada, 1986

(12) -El Centinela de Osuna., $n^{2} 33,19$, septiembre, 1886 
su vez lo era del .Colegio La Purísima Concepción. subvencionado por el Ayuntamiento, cuando se aproximaba la renovación del contrato con la Municipalidad, Rodríguez Durán se vio en la disyuntiva de elegir entre mantener la postura crítica del periódico o la subvención municipal para su Colegio. Optó por lo segundo, y Rodríguez Marín abandonó el periódico. A los pocos meses desapareció .El Ursaonense.

Decepcionado Rodríguez Marín por la actitud de Rodríguez Durán, a principios de febrero de 1886 saca un nuevo periódico .El Centinela de Osuna. dirigido por él. En el primer número deja claro la razón de ser del mismo: el control y la crítica de la gestión municipal. García Blanco saluda alegre e ilusionado a la nueva publicación en una carta que le envía a Rodríguez Marín donde diseña lo que debe ser el programa de acción de *El Centinela de Osuna*:

-... de V. el basta de adulaciones y mentiras; de V. el alerta contra el caciquismo, verdadera hidra de todos los pueblos de España; contra los dilapidadores de fondos públicos; contra los ignorantes; contra los oscurantistas, o gente que tienen al pueblo a oscuras de noche y: a la infancia y a la juventud de día....13

Valiente, sincero, hábil polemista, Rodríguez Marín irá denunciando cuantos casos de corrupción se den en el pueblo: el fraude del secretario del Ayuntamiento en la compra de gasógeno para el alumbrado público; los abusos cometidos por la directiva del Pósito Pío del Dr. Navarro, que se servía de los bienes de la institución sin cumplir su finalidad benéfica, los fraudes electorales, además de denunciar constantemente la situación de abandono material y moral en que se encontraba el pueblo.

Las represalias del Ayuntamiento y de los grupos dominantes no se hicieron esperar. La municipalidad quitó de la puerta de su casa una farola del alumbrado público que correspondía allí, mientras por las noches rondaban su calle unos cuantos matones armados de bastones y garrotes para lincharlo. ${ }^{14}$

La experiencia de ،El Ursaonense y la contundencia de Rodríguez Marín alejaron de las páginas de ‘El Centinela de Osuna* a los redactores y colaboradores del anterior semanario. Como el mismo Rodríguez Marín lamentaría, sólo contaba con la colaboración de García Blanco y de un joven poeta que se convertiría en su más fiel discípulo en los quehaceres periodísticos: Eulogio Jura do Fernández.

El 30 de enero de 1887, desilusionado, deja Rodríguez Marín la dirección de •El Centinela de Osuna», ocupándola Eulogio Jurado. En un

(13) -El Centinela de Osunan, $n^{2} 33,19$, septiembre, 1886

(14) -El Centinela de Osuna., n² 38, 24, octubre,1886; GUTIERREZ BALLESTEROS, José M²: Prólogo a Artículos periodísticos de D. Francisco Rodríguez Marín. Madrid, Atlas, 1957,
pág. IX 
artículo dirigido a sus sucesor titulado La Consigna le marca el camino a seguir por el periódico y le remarca: ‘ Guerra al caciquismo, que es la política que impera en Osunai: ${ }^{15}$

Con la llegada de Eulogio Jurado a la dirección, un autodidacta de familia humilde que había entrado en contacto con los intelectuales de la villa a través de las tertulias que se celebraban en casa de García Blanco, el periódico radicaliza sus críticas a los gobernantes locales y se define como el azote de los malos Ayuntamientos. La corporación liberal intenta varios procedimientos para acabar con el periódico: tras las amenazas al impresor de retirarle los trabajos que hacía para el Ayuntamiento, el periódico se imprime en Sevilla; denuncias, impedimentos para sellar el ejemplar que autorizaba su circulación, e incluso represalias familiares: el padre de Eulogio Jurado, empleado municipal, fue cesado en agosto de 1887.

A pesar de la tenacidad de Jurado, las presiones caciquiles van surtiendo efecto. Los anunciantes se retiran, los suscriptores dejan de pagar y en octubre de 1887 desaparece "El Centinela de Osuna* por falta de medios económicos.

Pero Jurado no desfallece y poco después saca un nuevo periódico. El 11 de enero de 1888 aparecía el primer número de "El Vigilante. Su pasión por Rodríguez Marín le lleva a imitar el nombre del fundado por su maestro. La línea que sigue en "El Vigilante" es la misma que mantuvo durante su etapa en la dirección de •El Centinela de Osuna*, llegando sus críticas hasta los tribunales de justicia, que le costaría a Jurado cuarenta y seis días de prisión. Finalmente, «El Vigilante desaparecería el 31 de mayo de 1889, justo diez días después de la muerte de García Blanco, lo que nos induce a pensar que fuera el anciano sacerdote quien financiaba la publicación.

.El Popular. es el resultado de un acuerdo entre dos directores de periódicos ursaonenses: Eulogio Jurado y Manuel Ledesma Vidal, otro autodidacta procedente del cenáculo de García Blanco y amigo de Rodríguez Marín. De temperamento más sosegado, ejercerá de filtro moderador de la impetuosa dialéctica de Jurado. A pesar de no ser un periódico tan agresivo como los anteriores, ello no fue óbice para verse libre de las persecuciones de los poderes locales. La Corporación conservadora restituyó en 1891 la mesa para la prensa en la Sala de Sesiones, que había sido retirada en tiempos de "El Centinela de Osuna. Sin embargo, cuando llegaron los liberales y "El Popular* emitió juicios nada favorables a los que estaban en el poder, no le retiraron la mesa, pero sí el papel, el tintero e incluso el quinqué que los alumbraba, "por cuya causa más de una vez tuvimos que ir provistos de bujía con que suplir la descortés conducta que

(15) RODRIGUEZ MARIN, F.: LLa Consignar. El Centinela de Osuna, n² 52, 30, enero, 1887 
observaba con nosotros el Ayuntamiento. ${ }^{16}$ Meses después se quejaría de la incomprensión de las autoridades hacia el periodismo local:

-... esta prensa objeto siempre de la animadversión de los que mandan, que no pueden ver con paciencia que haya personas o entidad que se permita el lujo de pensar por cuenta propia, apartándose de la obediencia más pasiva y que tenga además la audacia de recordar a las autoridades sus deberes y obligaciones. ${ }^{17}$

Desaparecido El Popular* a finales de 1898, un nuevo periódico del tándem Ledesma-Jurado salía en julio de 1902: •El Paleto. Es el semanario más longevo de cuantos se publicaron en Osuna -su último número salía a la calle en Julio de 1936- y por ello el paradigma de la sumisión de la prensa a los poderes locales. En los dos primeros años, mientras Eulogio Jurado estuvo de redactor-jefe, nos encontramos con un periódico inconformista, crítico, sin llegar a la acritud de los del S. XIX, pero muy en la línea de lo que había sido .El Popular.. A la muerte de Jurado en 1904 EEl Paleto. se hace más acomodaticio, hasta volverse en los últimos años anodino y aburrido. Más que un periódico es una hoja informativa, con artículos plúmbeos tomados de otras publicaciones, sin apenas noticias del pueblo y apolítico hasta la exageración. Ledesma Vidal había aprendido la lección, que como buen maestro no dudó en explicársela a Manuel Morales, otro autodidacta cargado de inquietudes que en octubre de 1922 sacaba a la luz un periódico crítico que gozó de una gran popularidad: ‘El Eco de Osuna». Tras pedirle consejos y colaboración en la campaña para el mejoramiento material y moral del pueblo al viejo Paleto, Ledesma Vidal le dice:

-Sepa el incipiente compañero que, precisamente por eso que él invoca, por nuestra experiencia, hace tiempo que nos hemos limitado a señalar con la dulzura de un ruego, más que con la acritud de una crítica descarnada y la dureza de un ataque impetuoso, los vicios y concupiscencia que nos roen, tristemente convencidos de que nuestros gritos enérgicos, gárrulos, rudos y alarmantes -ahí están para acreditarlo nuestras colecciones- han caído siempre en el vacío, sin conseguir estimular ni a los directores ni a los dirigidos. ${ }^{18}$

Los consejos no fueron oídos. Primero murió el periódico y después su director, fusila do en 1936 no por haber sido el último alcalde republicano, sino por las ampollas que había levantado cuando dirigió «El Eco de Osuna.

(16) -El Popular, $\mathrm{n}^{2} 39,7$, enero, 1894

(17) .El Popular, $n^{2} 73,2$, septiembre, 1894

(18) El Paleto, n² 987, 30, noviembre, 1922 